\title{
Lexicografia catingueira em vozes do mato
}

\author{
Lauana Sento Sé Vieira SANTOS ${ }^{1}$ \\ Cosme Batista dos SANTOS ${ }^{2}$
}

\section{Resumo}

Este artigo tem como objetivo apresentar resultados de uma pesquisa sobre o léxico e a lexicografia da cultura com base no livro Vozes do Mato, do escritor Esmeraldo Lopes. A obra contem narrativas sobre o cotidiano da vida na caatinga e as palavras que são trazidas em cada conto constitui um rico acervo do léxico catingueiro, ainda pouco valorizado na tradição lexicográfica brasileira. O pressuposto central do estudo é a pragmática lexicultural (Galisson, 2002; Barbosa, 2009), ou seja, o léxico como um meio privilegiado de acesso à cultura. Além disso, o trabalho traz uma revisão sobre a representação do sertanejo na literatura, considerando os vários sertões contrastantes (Melo, 2006). Logo, o artigo pretende mostrar como a palavra é um elemento imprescindível para conhecer a cultura e, ainda, introduzir uma metodologia de estudos e conhecimento da cultura, através da lexicografia.

Palavras-Chave: Cultura; lexicultura; Sertão; literatura.

\begin{abstract}
This article aims to present results of a research about the lexicon and the lexicography culture based in Vozes do Mato book, writer Esmeraldo Lopes. The book contains stories about the daily life in the caatinga and the words that are brought in each tale is a rich collection of catingueiro lexicon still unappreciated in Brazilian lexicographical tradition. The central presupposition of the study is pragmatic lexicultural (Galisson, 2002; Barbosa, 2009), so, the lexicon as a privileged means of access to culture. Moreover, this work brings a review about the representation about the country people in the literature, considering the many contrasting with the sertão (Melo, 2006). Thus, the article intends to show how the word is an essential element to know the culture and also to introduce a methodology of study and knowledge of the culture through of lexicography.
\end{abstract}

Keywords: Culture; lexicultural; Sertão; literature.

\section{Résumé}

\footnotetext{
${ }^{1}$ Estudante do $8^{\circ}$ período de Comunicação Social - Jornalismo em Multimeios, pela Universidade do Estado da Bahia, Campus III. Historiadora pela Universidade do Estado da Bahia, Campus IV, 2010. Email: lauanase@hotmail.com.

2 Orientador do trabalho. Professor do curso de Comunicação Social - Jornalismo em Multimeios da Universidade do Estado da Bahia - Campus III. Email: cosmebs.santos@gmail.com.
} 
Revista ComSertões

Cet article vise à présenter les résultats des recherches sur le lexique et de la culture de la lexicographie basé à livre Vozes do Mato, de l'écrivain Esmeraldo Lopes. Le livre contient des histoires sur la vie quotidienne dans la brousse et les mots qui sont portées dans chaque conte est une riche collection de lexique daguet, encore sous-évalué dans la tradition lexicographique brésilienne. La prémisse centrale de l'étude est la pragmatique lexiculturels (Galisson, 2002; Barbosa, 2009), à savoir le lexique comme un moyen privilégié d'accès à la culture. En outre, le travail apporte une critique de la représentation de l'arrière-pays dans la littérature, compte tenu de ses nombreux arrièrepays contrastées (Melo, 2006). Ainsi, l'article vise à montrer comment le mot est un élément essentiel de connaître la culture et aussi d'introduire une méthodologie d'étude et la connaissance de la culture par la lexicographie.

Mots-Clés: Culture; lexicuturels; Sertão; littérature.

\section{Introdução}

A cultura pode ser observada e acessada de diversas maneiras, dentre elas, a partir do universo lexical e da lexicografia relevante para uma comunidade ou para um determinado lugar. Com o intuito de tornar documentado e reacender a memória da cultura do semiárido baiano, o projeto "Estudos lexicográficos do semiárido baiano", com o apoio da Fundação de Amparo à Pesquisa do Estado da Bahia - FAPESB, está atuando em duas frentes de investigação, a saber, o levantamento do universo lexical culturalmente relevante no semiárido e a produção de uma lexicografia cultural, tendo em vista a preservação de valores, crenças e costumes ainda não ou pouco considerada na tradição dicionarística brasileira. No âmbito do projeto, estão sendo desenvolvidos vários subprojetos em comunidades distintas, incluindo a proposta de investigação intitulada "O léxico da cultura catingueira na obra Vozes do Mato de Esmeraldo Lopes", que visa documentar a cultura sertaneja através do acervo lexical recolhido nos contos da obra.

O objeto desta pesquisa, portanto, é o léxico catingueiro na obra literária Vozes do Mato (1992) do autor Esmeraldo Lopes, natural de Curaçá-BA. O autor que é pesquisador das raízes históricas e culturais da região do médio São Francisco, resgata em seu trabalho a identidade de um povo sertanejo/catingueiro e parte da memória social do campo. O livro lançado em 1990 é formado por 33 contos e dividido em três partes: Coisas daqui, Coisas que vêm de longe e Progresso. A primeira parte se refere "a uma época onde as ingerências do mundo exterior eram quase inexistentes (anos 40 a 60)"; a segunda parte se refere às influências exteriores, ou seja, aborda "o impacto de 
alguns elementos do mundo exterior, na vida da caatinga (década de 60 e 70) e, por fim, a terceira parte, que se refere às influências atuais, "pretende colocar em discussão a localização do caatingueiro e da caatinga no atual contexto histórico" (Gonçalves, 1992, p. 07).

Do ponto de vista metodológico, trata de uma pesquisa documental e se desenvolve através da leitura do livro e da classificação das palavras encontradas. Para a análise dos verbetes foi necessário fazer a conexão com a carga cultural ligada ao léxico do sertão, ideia trabalhada pela autora Lúcia Maria de Assunção Barbosa (2009), no conceito de lexicultura, ou seja, uma união entre o léxico e a cultura, que compreende a cultura de um grupo ou local, através das palavras, a cultura entrelaçada ao falar e entender de um grupo.

Além disso, foi necessário um mergulho na história do Nordeste, nas divisões regionalistas e no surgimento das literaturas sertanejas ou regionalistas, realizado através da obra A invenção do nordeste e outras artes, de Durval Muniz de Albuquerque Junior (2009). Assim como, as teorias geográficas da região do sertão, uma região defendida por Adriana Melo (2006) como não cartografável, região de contrastes entre o belo e o feio, o seco e o cheio, entre outros.

Os artigos de Riccardo Greco (2009) e Albertina Vicentini (1998) também nos auxiliaram na análise do livro Vozes do Mato. Esses autores ponderam várias obras que tratam do sertão, criticando aqueles que reacendem o discurso negativo do Nordeste e do sertão, aumentando o estereótipo criado desde a colônia, e enaltecendo os escritores que ajudaram a melhorar a imagem deste sertão tão rico em cultura, história, autenticidade, e de seu espaço diversificado em clima e vegetação.

Essa pesquisa pretende mostrar a importância de estudar o léxico de obras como Vozes do Mato, que trazem arraigadas o cotidiano e a cultura de um povo. Esse é um livro genuíno com os dizeres do sertão, uma cultura diferenciada e única, que apesar de ter se modificado com o passar dos anos, se mantém viva em sua essência até os dias atuais. 


\section{Referencial teórico}

O sertão desde o descobrimento do Brasil é idealizado de diversas maneiras, sendo-lhe atribuídos pontos positivos e/ou negativos. A princípio a divisão de território do Brasil era dada entre Norte e Sul, e sem especificar as características únicas dessas regiões. O diferente era o que determinava a visão de um espaço e, automaticamente, criavam-se estereótipos de um lugar.

Os discursos regionalistas da segunda metade do século XIX caracterizavam-se "pelo seu apego a questões provincianas ou locais, já trazendo a semente do separatismo" (Albuquerque Jr., 2009, p. 60), mas no século XX há uma tentativa de se criar uma identidade nacional, no intuito de unir um povo e suprimir as diferenças. Mas isso acaba tornando os regionalismos mais visíveis, assim como suas diferenças.

E é no final do século XIX e início do século XX, que a literatura regionalista se faz presente para afirmar a brasilidade por meio da diversidade. A literatura sertaneja, por exemplo, trata de diversos fatores relacionados a esse universo, alguns de forma a destacar a cultura rica que faz parte do sertão, mas também algumas parecem enfatizar o sertão de maneira depreciativa.

A literatura do Nordeste, discutida por Riccardo Greco (2009) que surge do interesse de se criar a identidade nacional do país, torna a regionalização algo forte na região Nordeste, pela qual escritores ora criaram uma idealização do sertanejo herói, ora anti-herói. Alguns autores enfatizam o passado, enquanto que outros preferiram criar um personagem próprio para a região, o sertanejo.

Entre as características do sertanejo nos romances regionalistas trabalhados por Greco (2009), que exaltam o sertanejo como um herói, estão: o sertanejo com força física, resistência ao clima e vegetação, com coragem (Ex: O Cabeleira, 1876, de Franklin Távora). Muitos autores do final do século XIX e início do XX transformaram o sertanejo em herói, esse regionalismo foi uma forma literária que recebeu influencia do Romantismo. 
Segundo Grecco (2009), quando o modernismo passa a fazer parte da literatura, esse discurso romântico e regional do sertanejo se modifica e se aproxima da realidade. E é nesse momento que surgem personagens que mais se importam com a própria sobrevivência e se assemelham a uma imagem "anti-herói”.

Vidas Secas (1938), de Graciliano Ramos, é uma das obras analisadas por Grecco (2009), que desconstrói esse discurso romântico-regionalista, concentrando-se na relação homem-região, e segundo o autor, é a partir dessa obra que surgem na literatura, histórias que trazem os aspectos dados ao Nordeste, como a seca, cangaço, entre outros.

Dentro da literatura regionalista, existe a chamada literatura sertanista, em que a autora Albertina Vicentini (1998) aborda os problemas na aceitabilidade dessa conceituação dos críticos. Alguns desses problemas se resumem em que tanto a literatura sertanista quanto a regionalista "têm obtido sua denominação a partir da matéria sobre a qual escrevem - o sertão ou região - e não necessariamente a partir da forma com a qual escrevem o fato literário enquanto tal" (Vicentini, 1998, p. 41). Temas que sempre se referem ao sertão evidenciando características do espaço geográfico, paisagístico e socialmente delineando as regiões, como também costumes e culturas locais, entre outros. Criam-se e reutilizam-se estereótipos, o que torna muitos livros com histórias semelhantes umas das outras.

Segundo Vicentini (1998, p. 43) as obras que utilizam muitos estereótipos sem a devida crítica são cheias de signos, que não "procuram estabelecer um sentido político, social ou humano [...] ou dar-lhe uma dimensão histórica de nosso tempo, capaz de reestabelecer outros sentidos e significações, ponto nevrálgico das renovações da literatura".

Essa visão representativa do sertão vem desde a época da colonização, em que o colonizador não levou em consideração a linguagem do colonizado. Onde podemos observar na etimologia da palavra "sertão", exposta por Vicentini, em que o adjetivo certum da expressão domicilium certum e a forma em português arcaico certão, "pode haver contagiado a significação (não a forma) de desertanum como 'lugar incerto', sertão, vocábulo que aponta sempre para um sítio oposto e distante de quem está falando" (Vicentini, 1998, p. 45). 
Mas além da etimologia o sertão carrega em si diversas significações, sejam elas científicas ou populares. O conceito geográfico que foi trabalhado, também vem da época da colonização do Brasil, em que o sertão passou a designar toda a área que se estendia além do mar, tudo que fosse o interior (Melo, 2006). Assim como "longínquo, selvagem, incivilizado (...) rico, isolado, sem lei, deserto, áspero, árido, pobre” (Melo, 2006, p.87).

Apesar desses estereótipos, tanto encontrados na literatura sertaneja ou regionalista, o sertão continua designando algo complexo e diversificado, que está em todos os lugares, um lugar difícil de determinar um espaço, rico em clima, vegetação e cultura.

A geógrafa Adriana Ferreira de Melo (2006) defende a ideia de que o sertão não é cartografável, não é um lugar em que se pode definir no mapa, pois existem muitas significações, mapeá-lo seria "contradizer a natureza ambígua, fugidia, descontínua, inconclusa, movediça, transitória" (Melo, 2006, p. 87). A não ser que se imagine um mapa metafórico, do qual é possível desenhar e redesenhar. Sua defesa é inteiramente de um sertão diversificado, multiplicidade em lugares, paisagens, territorialidades e significações.

O escritor Guimarães Rosa expressa esse pensamento da Adriana Melo, o qual ela utiliza como exemplo de que o sertão não é passível de mapeamento, pois segundo a autora, Rosa em seu livro Grande Sertão: Veredas, "recria o sertão a partir da mistura de uma geografia e uma história 'reais' e ficcionais" (Melo, 2006, p. 90). Em sua história, mostra um sertão ora pobre, ora rico, ora verde, ora seco, um sertão de contrastes, onde pode ser encontrado o belo e o feio, e ainda assim continuará sendo sertão, nas suas várias facetas e características. "Preencher com relevos de significação a palavra-espaço sertão é refletir sobre aquilo que é feito de mistura, da ambiguidade, do paradoxo" (Melo, 2006, p. 102).

No livro Vozes do Mato (1992) essa identificação sertaneja é forte, além disso, Esmeraldo Lopes traz contribuições no sentido de afirmar a definição de uma cultura catingueira no lugar de semiárido, ou seja, busca construir através de sua produção narrativa e descritiva, quase fotográfica, uma afirmação da cultura catingueira. Então, no lugar de conceitos genéricos, abstrações vagas, como sertão, semiárido, o autor 
Revista ComSertões

insiste na cultura catingueira e, em seu livro, especialmente, no capitulo que trata do tópico "Coisas daqui", o autor retrata, no sentido mais fotográfico da palavra, os elementos que sustentam essa afirmação, a identidade do vaqueiro, os seus modos de vida, as cidades, etc.

Ao ler e analisar o livro Vozes do Mato, diante de tantas outras obras que muito fala do sertão, percebemos que a literatura tem um papel muito importante no processo de divulgação da cultura sertaneja, e é a partir dessa análise que o conceito de lexicultura se faz presente. Esse é um conceito trabalhado por Lúcia M. A. Barbosa (2009), proposto por Robert Galisson (1987), como um meio de acesso às culturas e, em seus estudos, defende a importância de se estudar as palavras para além dos signos, de trazer as concepções culturais das palavras para a compreensão real delas. Para Barbosa (2009, p. 31), o léxico é a unidade da língua que permite emitir e compreender os significados da cultura, afinal ao léxico estão ligados aspectos "cognitivos, sociais e culturais de uma língua".

Por este motivo, as palavras trazem em si uma carga cultural muito grande que reflete diretamente na identidade cultural de uma sociedade através da língua e essas concepções culturais das palavras são compartilhadas dentro de uma sociedade. Nisso está configurado o conceito de lexicultura como o estudo do léxico implicado na realidade cultural, ou seja, a palavra como material linguístico implicado na realidade cultural investigada.

Segundo Barbosa (2009, p. 33). a lexicultura "mostra-nos a singularidade e a diversidade dos lugares onde a cultura pode ser encontrada em uma língua, (...) o léxico é o nível de descrição linguística mais diretamente ligada à realidade extralinguística". Esse termo vem da união das palavras léxico e cultura, a primeira que nos remete ao conjunto de palavras de uma língua, e a segunda, "conjunto de manifestações por meio das quais se expressa o cotidiano de um povo" (Barbosa, 2009, p. 33). Ao fazer o estudo no léxico e pelo léxico, o aprendiz em outra língua compreende melhor seu significado além de conseguir alcançar a cultura por trás das palavras.

Nem todas as palavras possuem um significado além daquele disponibilizado nos dicionários, mas as que possuem são conhecidas por palavra com carga cultural compartilhada (CCC ou CCP), que consiste no valor acrescentado ao léxico, "que é 
Revista ComSertões

conhecido e compartilhado entre os membros pertencentes a uma cultura e constitui fator de aproximação e de reconhecimento mútuo" (Barbosa, 2009, p. 34). Palavras que pertencem ao patrimônio coletivo, muitas delas são mobilizadas mais pelo significante do que pelo significado do signo.

O que importa nesse estudo é em como essas palavras evocam esse dado cultural e coletivo, é ir além do significado. Essas palavras podem evocar imagens, produtos, lugares, costumes, crenças, superstições e até mesmo comportamentos e regras de conduta. No livro, "Vozes do Mato, em especial, na primeira parte que se refere às "Coisas daqui", veremos como, ao lado de uma construção de imagens da cultura catingueira, há igualmente o esforço da seleção lexical em que essas imagens estão refletidas com uma carga cultural compartilhada entres os povos da caatinga.

\section{Metodologia}

A metodologia utilizada para a realização deste trabalho é a pesquisa bibliográfica e documental, e consistiu na análise e coleta de dados na obra literária Vozes do Mato e leituras teóricas que ajudaram a compreender o cenário e cultura do sertão. Essas leituras foram realizadas nos primeiros meses da pesquisa e consistiram em assuntos tais como: os múltiplos conceitos de sertão sendo ele geográfico, histórico ou/e cultural, a literatura sertaneja, e os conceitos de lexicografia e lexicultura, que se aplicam ao objeto de pesquisa estudado.

A partir da leitura dos contos da obra Vozes do Mato, os verbetes foram sendo selecionados e organizados em uma ficha lexicográfica, divididos em colunas com: o significado da palavra a partir do livro, sua classificação gramatical, gênero da palavra, o contexto que traz um exemplo do uso da palavra em uma frase, retirada do próprio livro e o significado encontrado nos dicionários oficiais, aceitos pelo MEC (Ministério de Educação e Cultura), como: o Dicionário Escolar da Língua Portuguesa, de Francisco da Silveira Bueno e o Aurélio versão eletrônica.

Esse levantamento lexical foi importante para o estudo lexicultural e etnolexicográfico da pesquisa. Os critérios de seleção das palavras foram feitos de 
Revista ComSertões

acordo com a nossa concepção do que caracteriza o povo catingueiro, independente do mesmo verbete já fazer parte de outros lugares e contextos brasileiros.

\section{Resultados Alcançados}

O resultado deste trabalho de pesquisa consiste na confecção e publicação do glossário piloto, enquanto produto final realizado a partir de leituras e estudos relacionados à lexicultura e ao sertão, com verbetes selecionados da obra literária Vozes do Mato, que pretende auxiliar na construção da identidade regional além do ensino na cultura sertaneja.

O glossário tem 342 verbetes distribuídos em ordem alfabética e estão organizados com classificação da palavra, significado e exemplo. Cada item do quadro de classificação das palavras foi pensado em como esses verbetes deveriam ser distribuídos e explicados num dicionário alternativo. Essa classificação foi definida após leituras e estudos realizados em grupo, chegando à conclusão que os dicionários oficiais nem sempre abrangem os significados de cada região a determinadas palavras. Afinal, ao acrescentar a compreensão cultural da qual o verbete faz parte, facilitaria o processo de ensino-aprendizagem dentro do Brasil, ou fora dele, como língua estrangeira, ao inserir o aprendiz ao cotidiano e à cultura de uma sociedade.

Os verbetes estudados carregam toda a carga cultural relacionada ao sertão, pois além de nos apresentar novas palavras, o livro nos revela uma cultura contada através do cotidiano, encontrado em suas páginas. Uma história contada na experiência de vida de um autor, que também na saudade, resolveu registrar tudo que viveu em sua infância e nas histórias que ouvia.

Entre verbos, substantivos, adjetivos, expressões e etc., o livro traduz um falar diferente e ao mesmo tempo semelhante ao restante do país. O Brasil, país tão miscigenado em raças, também se mistura em línguas, expressões, palavras. Muitas delas não são muito diferentes nas significações como futucar, acudir e acocorar. Em alguns lugares somam mais significados, e os verbetes não são desconhecidos. Já o adjetivo ideiado e os substantivos homaiada e lordeza são palavras que já tem diferenciações com o falar "brasileiro". Palavras que já trazem um significado singular 
com o falar sertanejo e catingueiro. A análise realizada é baseada nas palavras catalogadas, e na história por trás de cada signo.

Ricos? Lá, lá na rua, no prosear das calçadas, tem. São poucos, mas vivem no folgar da vida, botando vaqueirice para cuidar do criatório. Ficam lá, esperando pelo governo. Não gostam da vida de labuta, não. Gostam é de lordeza, conforto, comida boa... Esse negócio de roupa bonita e macarrão todo dia não é coisa de quem labuta. No tipo de vida que a gente tem, não cabe enfeite, nem de barriga, nem de embelezamento. Só tem lugar para decência. Quem inventa de imitar os ricos da rua só faz é acabar o criatório e cair na pindaíba. (Gonçalves, 1992, p. 18).

Seguem alguns verbetes com exemplos retirados da obra Vozes do Mato:

- BURRAGEM: substantivo feminino 1. Cometer um erro. 2. Burrice. "O cão de rabo abanando é doido pra alguém fazer burragem" (p. 14).

- CAVUCAR: verbo 1. Futucar, mexer. "Todo o gado cheira o couro, todo o gado começa a cavucar o chão, todo o gado começa a berrar" (p. 38).

- CURCUVIADO: substantivo masculino 1. Curvas. "A estrada estirada, cheia de curcuviado com altos e baixos, mais parece uma cobra andando" (p. 26).

- ESPINAR: verbo 1. Sair de modo estabanado, saltar fugindo de uma situação. "As ovelhas espinam porteira a fora, enquanto o vaqueiro faz a arrumação e as toca na direção certa da estrada do seu lugar” (p. 22).

- GROZAR: verbo 1. Esfregar. 2. Roçar. “Tem a zuada das galhas se grozando, mexidas pelo vento" (p. 29).

- HOMAIADA: substantivo feminino 1. Grupo de homens. 2. Muitos homens juntos. "A homaiada, no terreiro, ajeita os animais tirando-lhes os arreios, levando-os para o peador" (p. 20).

- LORDEZA: substantivo feminino 1. Estado ou condição de quem é lorde. Uma pessoa que tem lordeza é uma pessoa que gosta de viver no luxo. "Tem uns que não gostam da vida de labuta não. Gostam é de lordeza, conforto, comida boa [...]" (p. 18). 


\section{Considerações Finais}

A cultura é a alma de uma sociedade ou grupo. Pois ela retrata toda uma história de uma vida anterior às nossas, que vem de nossos antepassados e é passado de geração a geração. A cultura nos molda, transforma quem somos, e os que pertencem ao mesmo grupo têm algo em comum, nem que seja o amor pela sua terra e tradições.

Ao longo deste trabalho foi desenvolvida uma pesquisa qualitativa e quantitativa, através do acervo e objeto de pesquisa, o livro Vozes do Mato. Nesse trabalho foi possível interagir com outros autores que muito discutiu sobre o sertão, a literatura, a lexicografia e a cultura. Conteúdos que muito se relacionam com o objeto, já que o mesmo, através da literatura e das palavras, traz toda a cultura enraizada de um povo sertanejo que sobreviveu até mesmo ao chamado "progresso" da sociedade.

A linguagem é um elemento cultural forte, que define e une mais ainda uma sociedade. Ao trabalhar com os verbetes, podemos concluir que eles são muito fortes culturalmente, pois as palavras também retratam o cotidiano de um povo, e o verbete vai desencadeando toda uma história de vida que faz parte da realidade de quem vive, nesse caso, na zona rural do sertão. E podemos usar como exemplo, o substantivo curcuviado, que não possui no dicionário oficial do Aurélio e que significa "curva", ou do adjetivo ideiado, em que a definição se refere a uma expressão, adjetivando dessa maneira os bois difíceis de serem pegos, ou um "boi enfeitiçado". É por isso que o conceito de lexicultura é o principal utilizado nesta pesquisa, pois compreende toda a complexidade por trás das palavras que estão sendo analisadas.

Ao final deste trabalho foi realizada a catalogação, análise e investigação dos significados de 342 verbetes que compõem o Glossário Vozes do Mato. A conclusão de todo o trabalho se dará com a publicação oficial desse glossário, que tem o intuito de apresentar à comunidade acadêmica uma nova alternativa de dicionário, que servirá para consultas e aprendizado, para a comunidade, estudantes de todos os segmentos, e professores. Esse produto também abre discussões sobre essa nova conceituação de caatinga em detrimento da conceituação de semiárido. Esse glossário tem o intuito de 
Revista ComSertões

agregar os significados de cada signo referente ao sertão, caracterizando-o e trazendo seu significado cultural, que é o mais importante.

\section{Referências Bibliográficas}

ALBUQUERQUE JUNIOR, Durval Muniz de. A Invenção do Nordeste e Outras Artes. São Paulo, $5^{\text {a }}$ edição, Cortez Editora, 2009.

BARBOSA, Lúcia Maria de Assunção. O conceito de lexicultura e suas implicações para o ensino-aprendizagem de português língua estrangeira. Revista Filologia e Linguística Portuguesa. São Paulo, Universidade de São Paulo, 2009. Disponível em: http://www.revistas.usp.br/flp/article/view/59812. Acesso em setembro de 2013.

BARBOSA, Lúcia Maria de Assunção. Figurações identitárias e culturais do Brasil em letras de canções sob a perspectiva de falantes de outras línguas. Revista do Programa de Pós-Graduação em Crítica Cultural. Alagoinhas, Universidade do Estado da Bahia, 2012. Disponível em: http://www.poscritica.uneb.br/revistaponti/arquivos/volume2-n2/12.FIGURACOES\%20IDENTITARIAS-E-CULTURAIS\%20-vol2-n2.pdf. Acesso em novembro de 2013.

GRECO, Ricardo. O sertanejo no sertão-mundo. Revista online do Grupo Pesquisa em Cinema e Literatura, Baleia na Rede. São Paulo: Universidade Estadual Paulista, 2009. Disponível em:

http://www.marilia.unesp.br/Home/RevistasEletronicas/BaleianaRede/Edicao06/6a_o_s ertanejo_no_sertao_mundo.pdf. Acesso em agosto de 2013.

GONÇALVES, Esmeraldo Lopes. Vozes do Mato. Juazeiro, 1992.

MELO, Adriana Ferreira de. Sertões do mundo, uma epistemologia. Belo Horizonte: Universidade Federal de Minas Gerais, 2011.

MELO, Adriana Ferreira de. Imagens do Sertão em Grande Sertão: Veredas. In: O Lugar-Sertão: grafias e resuras. Belo Horizonte: Universidade Federal de Minas Gerais, 2006, cap. 3, p. 86-121.

VICENTINI, Albertina. O sertão e a literatura. Revista de pesquisas e debates em ciências sociais, Sociedade e Cultura. Goiás, Universidade Federal de Goiás, 1998. Disponível em: http://www.revistas.ufg.br/index.php/fchf/article/view/1778. Acesso em agosto de 2013. 
